\title{
Roughness Effect on Corrosion of Gr-Cu -Ni Coated Steel in Saline Water
}

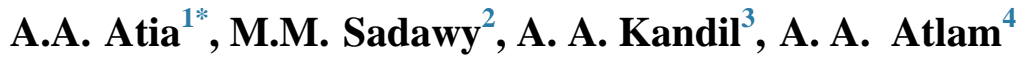 \\ ${ }^{1}$ Higher Technological Institute, P.O. Box 228,10th of Ramadan City, Egypt \\ ${ }^{2}$ Al-Azhar University, Faculty of Engineering, Mining and Pet. Dept., Nasr \\ City, P.O. Box 11371, Cairo, Egypt \\ ${ }^{3}$ Al-Azhar University, Faculty of Engineering, Mining and Pet. Dept., Nasr \\ City, P.O. Box 11371, Cairo, Egypt \\ ${ }^{4}$ Al-Azhar University, Faculty of Engineering, Mining and Pet. Dept., Nasr \\ City, P.O. Box 11371, Cairo, Egypt

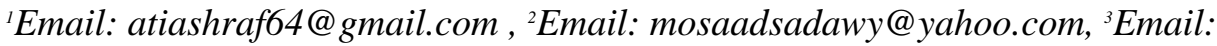 \\ akandil165@gmail.com, ${ }^{4}$ Email: ahmed_atlam45@yahoo.com
}

\begin{abstract}
Effect of surface roughness on corrosion behavior for carbon steel was coated by metallic layers Cu-Ni Reinforced with Gr layers. Surface finishing P320, P600 and P1200 mesh used until a mirror shiny surface before metallic coated with Gr layers at consecrations 0.25, 0.5, land $2 \mathrm{~g} / \mathrm{l}$ of Gr. First, X-ray diffraction), electron microscopy associated for carbon steel \& Gr and Microscopic test for coated specimens. The techniques were performed to study the effect of saline water (3.5\%) on the corrosion behaviors, Open circuit potential, Tafel polarization and impedance spectroscopy tests. At P320 Equivalent Circuit elements were decreasing but, Corrosion reaction's $R p$ was increased at 5 min and $0.25 \mathrm{~g} /$. And also, coating's Rpore with Electrolyte's Ru were increasing at 30 min for 0.5 $\mathrm{g} / \mathrm{l}$, and also coating's Rpore and Electrolyte's Ru were increased at $20 \mathrm{~min}$ for $1 \mathrm{~g} / \mathrm{l}$, At P600 ECE's were decreasing but, corrosion reaction's Rp was increased at $30 \mathrm{~min} 1 \mathrm{~g} / \mathrm{l}$, and also, coating's Rpore and Electrolyte's Ru were increased at $20 \mathrm{~min}$ for $1 \mathrm{~g} / \mathrm{l}$, and At P1200 ECE's were decreasing but, Coating's Ccoat was increased at $5 \mathrm{~min} 0.25 \mathrm{~g} / \mathrm{l}$, and also coating's Rpore and Electrolyte's Ru were increased at $0.5 \mathrm{~g} / \mathrm{l}, 30 \mathrm{~min}$.
\end{abstract}

Keywords: Carbon steel; Electrolyte; $\mathrm{Cu}$-Ni -Graphene oxide coating; Corrosion behavior

* Corresponding author.

E-mail address: atiashraf64@gmail.com (A.A. Atia). Tel:+2-109-1559986 


\section{Introduction:}

The multilayer metallic coatings lead to the proposal's enormous potential for improvement in performance relative to single-layer coating. [1], and corrosion is a significant reason for decay in industrial parts. So the advanced coatings improve in properties in their morphological, electrical, thermal, and mechanical characteristics [2],[3], Gr is applied as a corrosion inhibitor for metals. where a monolayer and multilayer graphene-coated onto metal surfaces have excellent barriers to oxygen diffusion, that renders the underlying metal inert from environmental oxidation [4]-[8].So, graphene-based anti-corrosion coatings are used to improving surface properties of a substrate [9], [10]. Gr consists of carbon atoms that are strongly bonded to form a hexagonal network, graphene has been generating sustained interest for many fields [11], [12].Cu- plating is used with both $\mathrm{Ni}$ and $\mathrm{Cr}$ plates and is considered to be the most preferable coating surface due to its ability to be spreader in a uniform layer and ductile with no pores with the advantage of polishing capability if several layers are used [13].Ni-plating can be used as a protecting agent against corrosion that can in the abrasion applications, resisting agent against the corrosion also as smoothing substance for other materials [13], [14].Multilayer chromium, nickel, and copper on the carbon steel, lead to copper and nickel are initially anodic versus chromium and become cathode versus carbon iron, when the electrolyte reaches the inner layer, galvanic corrosion take place [15].Resistance of a metal to electrochemical degradation was increasing by a coating of $\mathrm{Cu}$ with Gr. So, electrochemical characterization in aggressive CL environment shown changes in development of anti-corrosion coatings by using graphene layers [16]-[18]. Ni-graphene coatings provide corrosion resistance, which solves corrosion protection problems in the oil and gas industry [19],[20],[21]. Electrochemical for coating multilayer graphene improve the corrosion resistance of a $\mathrm{Cu}-\mathrm{Ni}$ alloy [15], [22]-[24].

\section{Materials and Methods:}

\subsection{Materials:}

\subsubsection{Specimens of carbon steel ST37-2}

Carbon steel ST37-2 is produced by the Arab Company for Special Steel (Arkosteel) in Saddat City -Egypt with the following characteristics, Chemical analysis is measured at SPECTRO MAXX at EVACO Co. in 10th of Ramadan city, Egypt. which is shown in the following table 1

Table 1. Chemical Composition of Steel (37.2)

\begin{tabular}{|c|c|c|c|c|c|c|c|c|c|c|c|c|}
\hline $\begin{array}{c}\text { Chemical } \\
\text { elements }\end{array}$ & $\mathbf{C}$ & $\mathbf{S i}$ & $\mathbf{M n}$ & $\mathbf{P}$ & $\mathbf{S}$ & $\mathbf{C r}$ & $\mathbf{M o}$ & $\mathbf{N i}$ & $\mathbf{C u}$ & $\mathbf{A l}$ & $\mathbf{C o}$ & $\mathbf{F e}$ \\
\hline$\%$ & $\begin{array}{c}0.1 \\
2\end{array}$ & 0.3 & 0.42 & $\begin{array}{c}0.01 \\
4\end{array}$ & 0.01 & 0.04 & $\begin{array}{c}0.00 \\
3\end{array}$ & 0.02 & 0.05 & 0.02 & 0.00 & 99 \\
\hline
\end{tabular}

- Scanning electron microscope (SEM) of carbon steel fig.1.

2.1.2. The characterizations of graphene oxide:

Graphene oxide was purchased from the company "Graphene laboratories ,Inc., indiamart, India " Color : broan,Thickness : 1 atomic layer- at least $60 \%$,Flake size : 0.5 - microns, Composition : Carbon 97\%,Oxgen ( $20 \%$ ), Single layer graphene oxide solution ,Item no: sgraphene -001, which, it is prepared by Hummer's method which is oxidized graphene formed from oxidizing crystal graphite with a mixture of sulfuric acid, sodium nitrate, and potassium permanganate. Graphene Oxide is represented in fig.1., (b) graphene oxide characteristics as FE-SEM image, (c) graphene oxide characteristics as EDX spectroscopy analysis, and (d) graphene oxide characteristics as XRD pattern. 
(a)

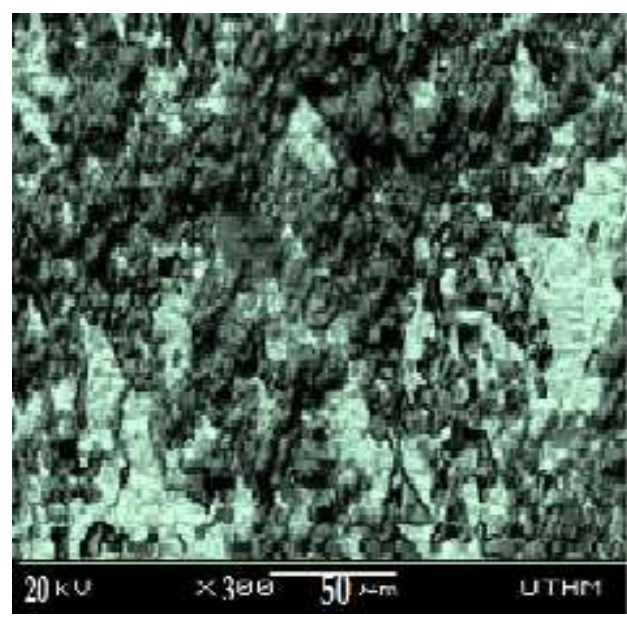

(b)



(c)

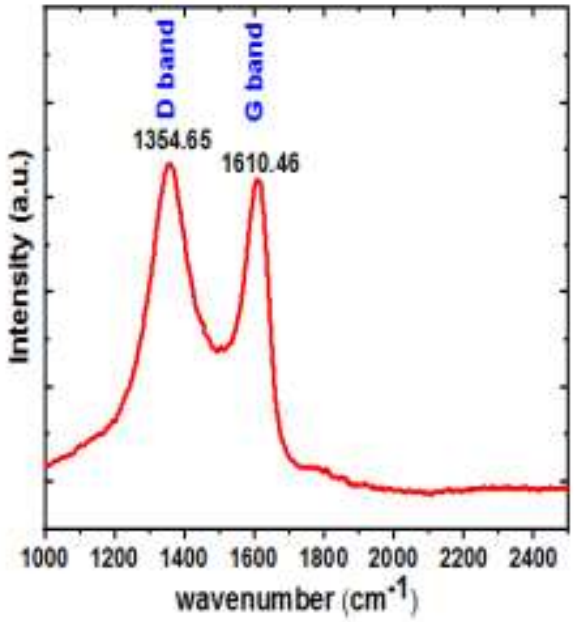

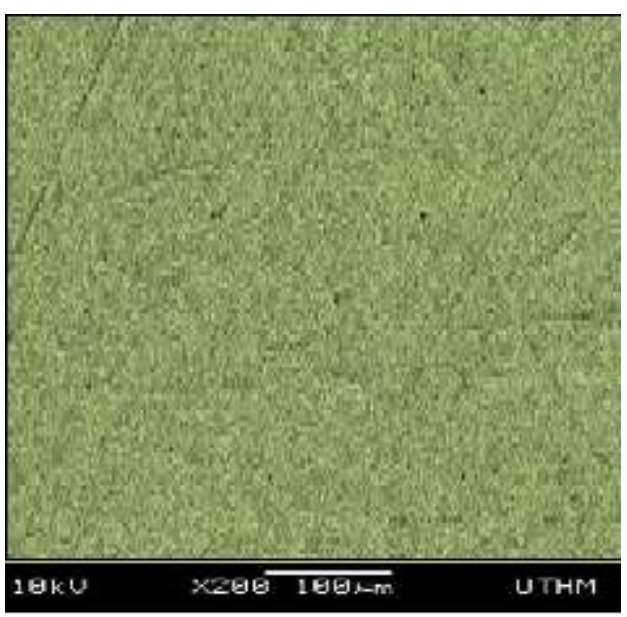

(d)

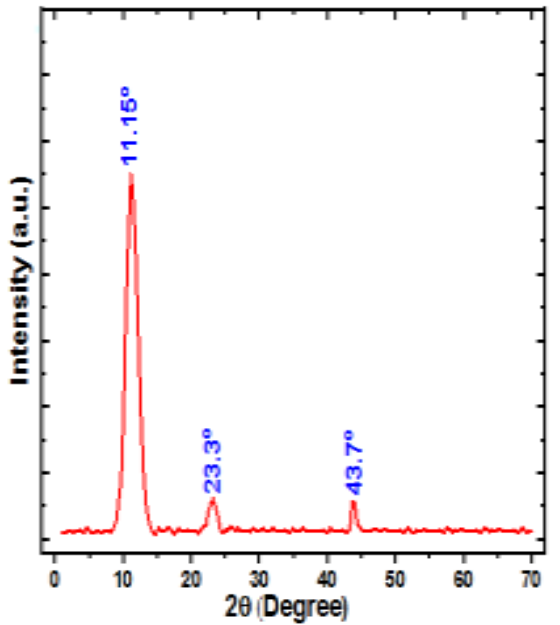

Figure 1. a- Scanning Electron Microscope (SEM) of Carbon Steel ,b-d; Graphene Oxide Characteristics as, (b) FE-SEM Image, (c) EDX Spectroscopy Analysis, and (d) XRD Pattern of Graphene Oxide.

\subsection{The schematic diagram of research sequence for metallic layers coated with graphene:}

The searches can be summarized in the following preparation of specimens of the substrate, preliminary 5 samples for metallic coating, electroplating of graphene oxide, testing morphology of coating, and potentiodynamic scan all are represented in fig.2. The schematic diagram of the research sequence for metallic layers coated with graphene.

2.2.1. $\mathrm{Cu}$ - Ni- Metallic coating with $\mathrm{Gr}$ preparation processes

Preparations of specimens of substrate take place with the operations cutting, holing, grinding, emery, polishing, removal of grease, oxides and salts. Prior to the deposition of the coatings on Carbon steel $30 \mathrm{X} 100 \mathrm{X} 3 \mathrm{~mm}$ dimensions were polished with struers ${ }^{\circledR}$ papers silicon carbide grades 320, 600 and 1200 mesh until a mirror shiny surface, Preliminary 5 samples were used to identify the suitable $\mathrm{Cu}, \mathrm{Cu}$ and $\mathrm{Ni}$ plating conditions fig.2. for reach the appropriate conditions for the research five samples to reach the research, Electroplating of graphene oxide coating is achieved by $44 \mathrm{ml}$ of 
deionized water and $308 \mathrm{ml}$ of acetone to dissolve the graphene oxide for $90 \mathrm{~min}$ in the ultrasonic 100 watt $-40 \mathrm{kHz}$ to activation then added to electrolytes with different ratio $0.25,0.5,1$ and $2 \mathrm{~g} / \mathrm{l}$. Therefore, the graphene oxide is coating by electroplating between the coated metallic layers of $\mathrm{Cu}$, $\mathrm{Cu}$ and $\mathrm{Ni}$ with two similar electrodes by the cell is represented in fig.2.

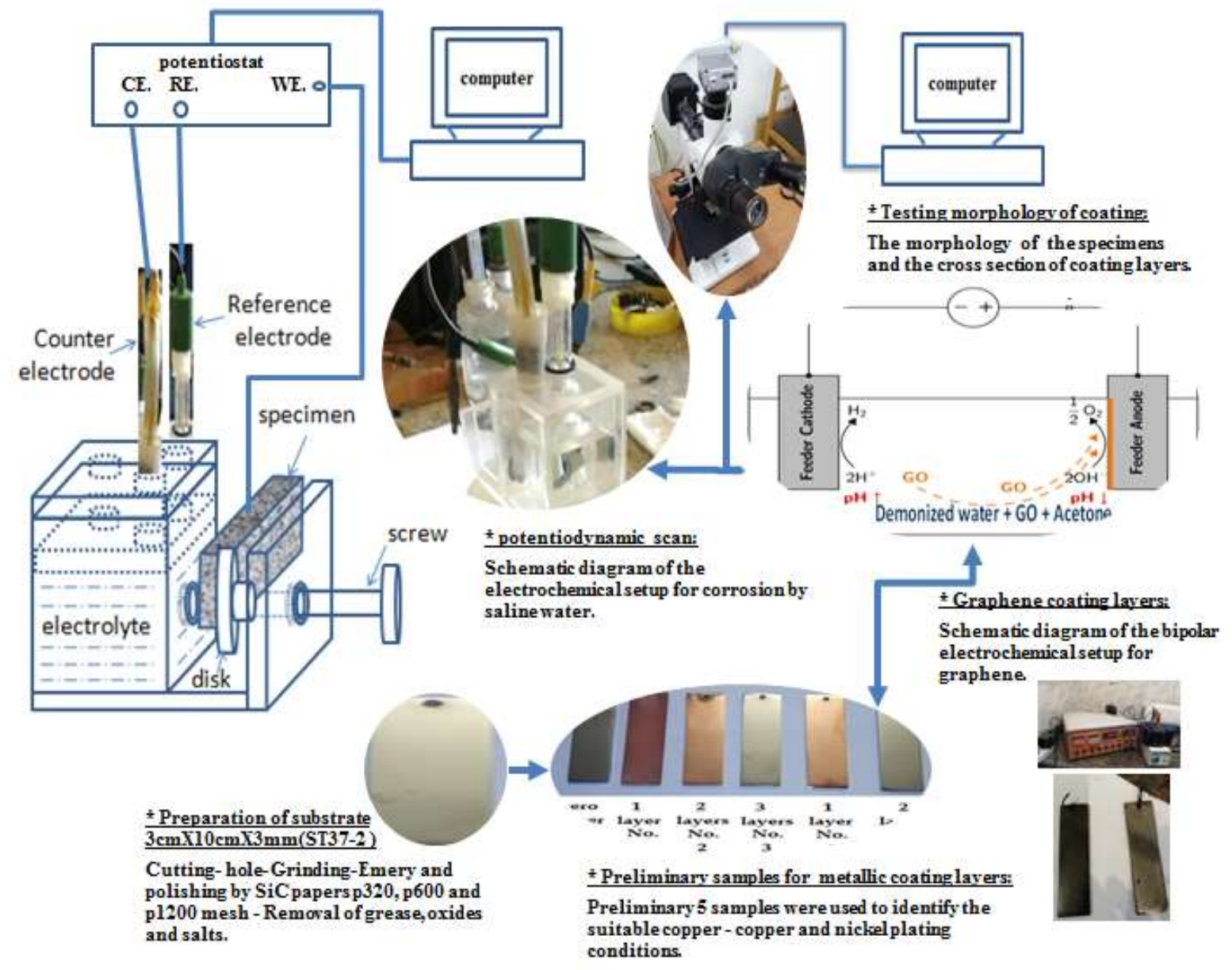

Figure 2. Schematic Diagram of Research Sequence for Metallic Layers Coated with Graphene.

2.2.2 Experimental setup design for testing morphology of coating:

$\mathbf{z}$ The morphology of the prepared specimens are tested by the optical microscope CIM® with digital camera moticam 2300 - 3.0MPixel USB 2.0 , U S A shows morphology of the specimens and the cross section in fig. 2 .

\subsection{Electrochemical measurements:}

2.3.1. Experimental setup design for testing corrosion of coating

The corrosion of prepared specimens are tested by the designed cell which consists from three electrodes reference calomel electrode Rf (HI 5412), Pt counter electrode and specimen. They are immersed in saline water as electrolyte as shows in the Figure 2.

\subsubsection{The corrosion techniques}

An electrochemical process is electrochemical corrosion monitoring techniques are based on the corrosion of metals in solutions of electrolytes. Where, the electrochemical techniques are suitable for 
corrosion of metals in media with high electrical conductance. And also, if corrosion reactions have an electrochemical nature, electrode potential, electric current and electrical resistance formed on the metal surface are the main characteristics of corrosion. So, we measure these three parameters characterize and monitor the corrosion of metals in electrical conductive media[24].

The corrosion techniques were tested by Gamry (PCI4/300®) instrument ,U S A where, the various factors were achieved on the corrosion behavior of carbon steel 37-2 coated by metallic layers (copper-copper-nickel) reinforced with graphene by the following techniques:

2.3.2.1 open circuit potential, Eoc:

For gamry's software, the open circuit potential, Eoc is the equilibrium potential assumed by the electrode in the absence of electrical connections to the electrode. So, all potentials are specified as the potential of the working electrode with respect to the reference electrode "vs. Eref"or this open circuit potential "vs. Eoc". So, the equations used to convert from one form of potential to other shown in following:

E vs. $\mathrm{Eoc}=(\mathrm{E}$ vs. Eref $)-$ Eoc

E vs. Eref $=(E$ vs. Eoc $)+$ Eoc

The potentials are versus Eref or versus Eoc, the sign is used positive a potential, which, more anodic it is.

\subsubsection{The Tafel polarization test:}

Potentionstat records an applied current to cell that provides an increase in potential. Where, potential drives a reaction at the anode or cathode, is observed a current. That is, a potential where a total anodic current equals a total cathodic current is an open-circuit potential (Eoc), a potential swept across a range and a current is measured. [25].

Corrosion occurs at a rate specified by the equilibrium between opposing electrochemical reactions. First is the anodic reaction, metal oxidizes, releasing electrons into the metal. Second is the cathodic reaction, a solution form (usually $\mathrm{O}_{2}$ or $\mathrm{H}^{+}$) is reduced, removing electrons from the metal. By equilibrium of two reactions, the flow of electrons from each reaction is balanced, and no net electron flow (electrical current) occurs. The two reactions can happen on one metal or on two dissimilar metals (or metal sites) that are electrically connected [26].

\subsubsection{The electrochemical impedance spectroscopy (EIS):}

$\mathrm{By}$, applying an $\mathrm{AC}$ potential to an electrochemical cell and then measuring the current through the cell to get electrochemical impedance [27], [28].

The impedance attitude of coating is explored where most paint coatings degrade with time, resulting in an attitude more complex. After certain of time, water penetrates into the coating and forms a new liquid/metal interface under the coating. Corrosion phenomena can happen with the new interface. According to the simple equivalent circuit elements are Ccoat, the capacitance of coating, its value is much smaller than $\mathrm{CdL}$, a double layer capacitance, with, units that are $\mathrm{pF}$ or $\mathrm{nF}$, not $\mu \mathrm{F}$. Rpore, pore resistance, and is the resistance of coating for ion-conducting paths develops in. The paths may not be physical pores full of electrolytes. On the metal side of the pore, an area of the coating has divided and a bore filled with an electrolyte solution has formed. with, very different than the bulk solution outside of the coating.Ru, electrolyte resistance, Rp, polarization resistance [28]-[30].

\subsubsection{Corrosion Rate Measurement (mpy)}

The rate of corrosion $\left(C_{R}\right)$ is directly proportional with its corrosion current density $\left(i_{\text {corr }}\right)$ in a given environment in according the relation [3], [31] :

$$
C_{R}=0.13 \times i_{\text {corr }} \times\left(\frac{\mathrm{e}}{\rho}\right)
$$


This equation calculates $C_{R}$ in $(\mathrm{m} / \mathrm{y})$, e and $\rho$ are equivalent weight and density of carbon steel, respectively. The data of corrosion rate indicate that the nanoparticle coatings led to decreasing in corrosion rate of carbon steel.

The applied coatings were evaluated by corrosion current densities for uncoated and coated specimens which, used to calculate protection efficiencies (PE\%) as follows [32]:

$$
\mathrm{PE} \%=\left[1-\frac{\mathrm{i}_{\text {corr }_{\text {coated specimen }}}}{\mathrm{i}_{\text {corr }} \text { uncoated specimen }}\right] \times 100
$$

The best efficiency was for $\mathrm{Cu}-\mathrm{Ni}-\mathrm{Gr}$ coating. Surface porosity fraction evaluated by both potentiodynamic polarization and indentation measurements. and, the porosity percentage (PP\%) is calculated by the following equation [32]:

$$
\mathrm{PP} \%=\left[\frac{\mathrm{R}_{\mathrm{P}_{\text {uncoated specimen }}}}{\mathrm{R}_{\mathrm{P}_{\text {coated specimen }}}}\right] \times 10^{\frac{-\Delta \mathrm{E}_{\text {corr }}}{\mathrm{b}_{\mathrm{a}}}} \times 100
$$

So, the polarization resistances of the uncoated $R_{p}$, uncoated, the polarization resistances of the coated $\mathrm{R}_{\mathrm{p}}$, coated samples, the corrosion potential difference between them, $\Delta \mathrm{E}_{\text {corr }}$, and $\mathrm{b}_{\mathrm{a}}$ is the anodic Tafel slope of the uncoated sample. The lowest porosity was found for $\mathrm{Cu}-\mathrm{Ni}-\mathrm{Gr}$ coating [32].

\subsection{Microstructural characteristics of surface analysis:}

This was shown in the XRD diffractograms of GO/Cu-Ni coatings with concentrations; (a) 0.0, (b)

0.5 , (c) 1.0 and (d) 2 (g/l ) of GO on carbon steel fig.3.

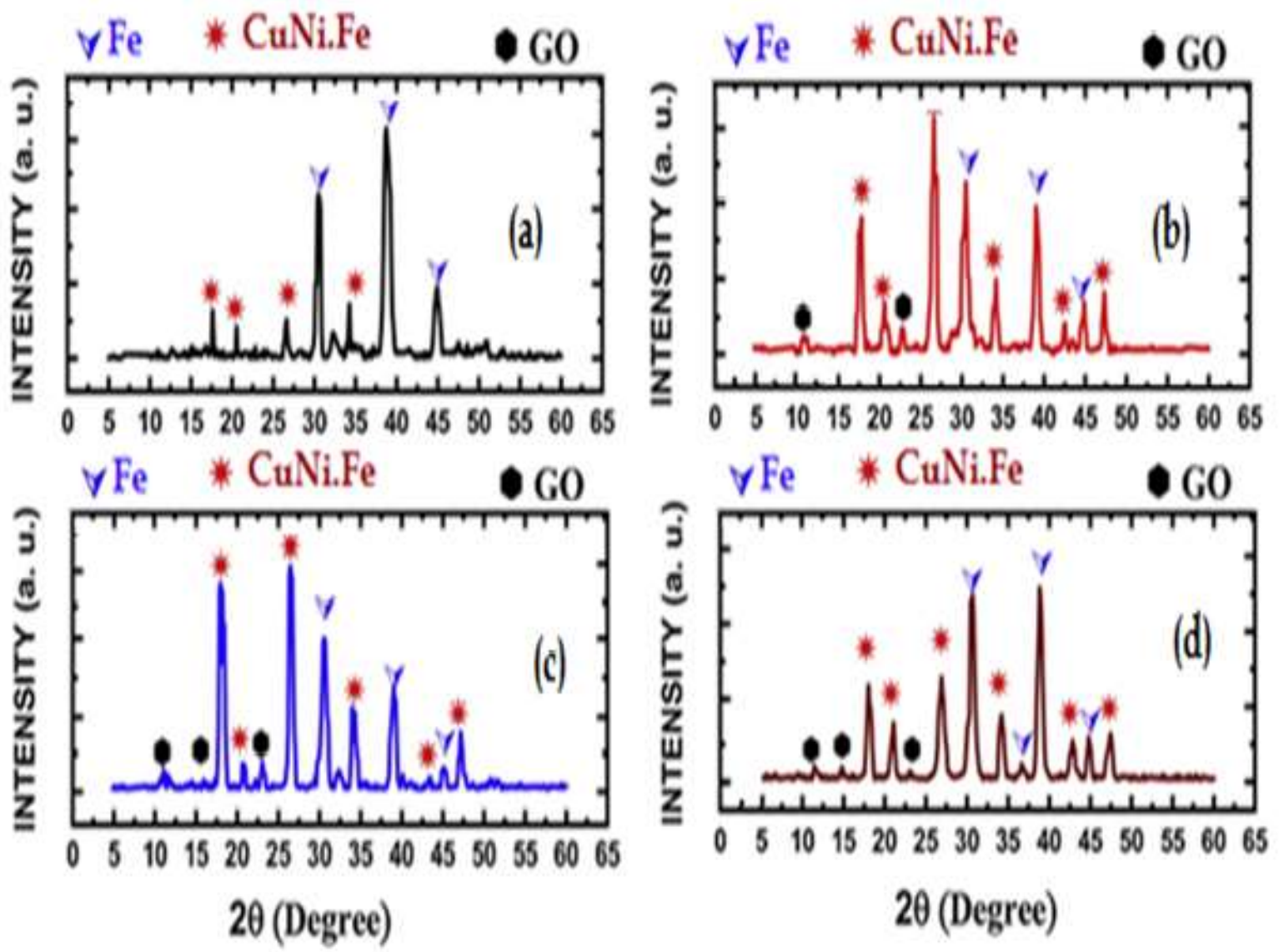

Figure 3. a-d; the XRD Diffractograms of GO/Cu-Ni Coatings with Concentrations; (a) 0.0, (b) 0.5, (c) 1.0 and (d) 2 (g/l ) of GO on Carbon Steel. 


\section{Results and discussions:}

\subsection{Optical Observations of cross section and morphology for coating:}

3.1.1 Cross-sections and morphology of electroplating for 1, $2 \mathrm{gr} / \mathrm{L}$ of Graphene at 10, 20 min for P320, P600and P1200:

For cross-section, the first layer was soft next to the substrate; the two layers $\mathrm{Cu}$ - graphene were hard spongy form, the two layers $\mathrm{Cu}$ - graphene brittle spongy form and $\mathrm{Ni}$ - graphene hard high strength spongy form with thickness 430.9 um, and For morphology, there were spongy form and had few cavities on surfaces of the coating fig.4.

(a)
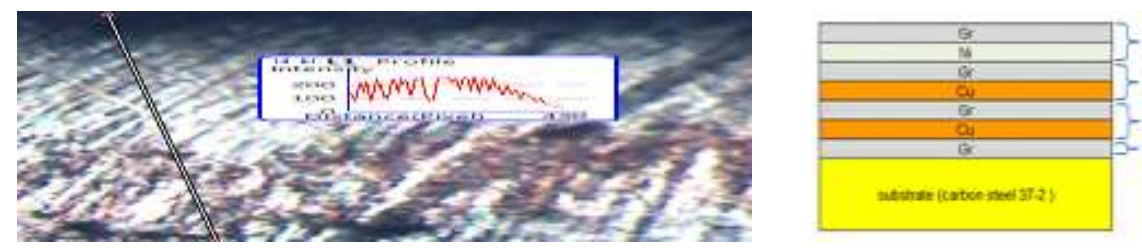

Hard high strength with spongy Brittle with spongy Hard with spongy Soft

(b)
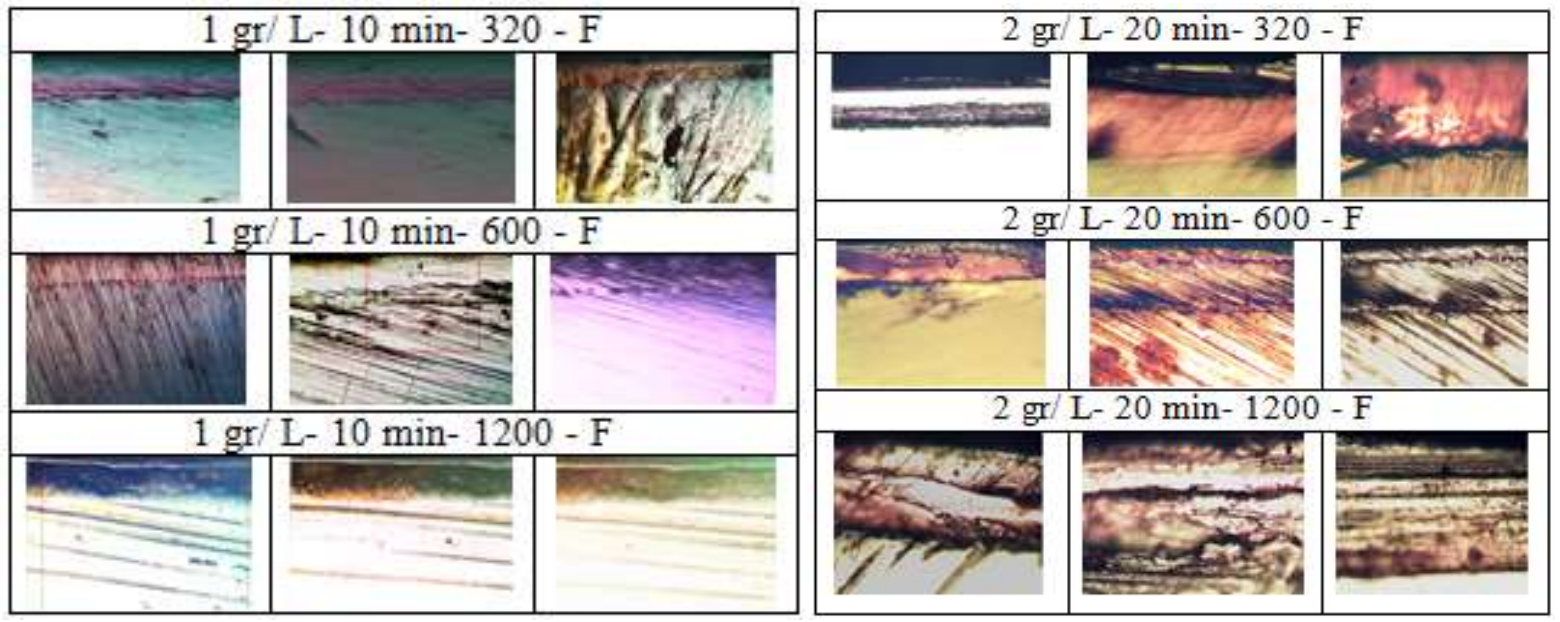

(c)
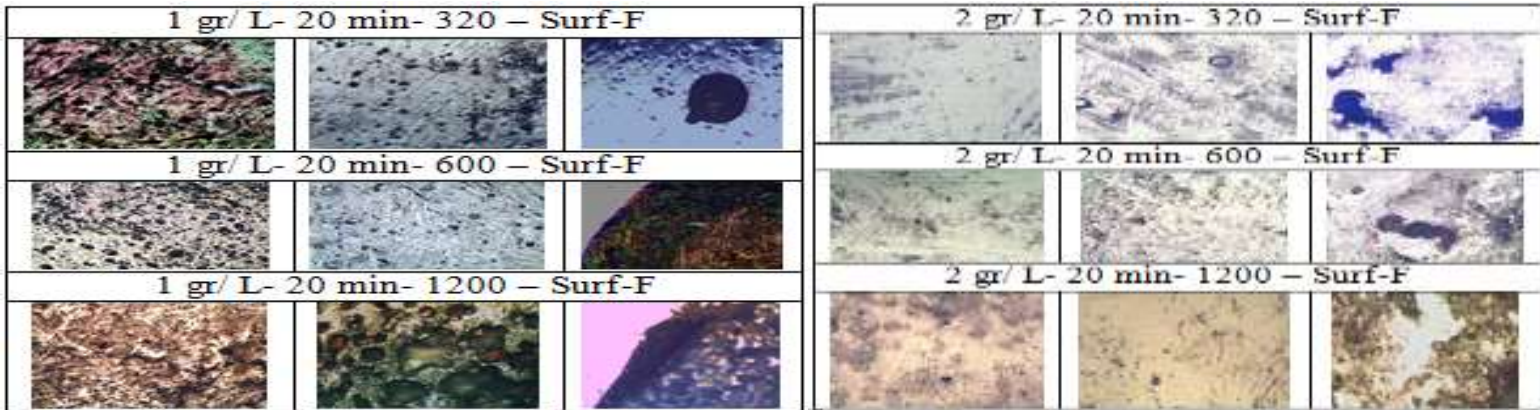

Figure 4. Cross-Section and Morphology of Coating (a) Sketch of Layers with Fatures, (b) Cross-Section and (c) Morphology of Coating for 1, 2 g/l Graphene with P320, P600 and P1200 


\subsection{The open circuit potential, Eoc:}

The electrochemical measurements took place by Gamry PCI300/4 Potentionstat with a computer, three-electrode cell, a specimen as a working electrode with an active area of $1 \mathrm{~cm} 2$, a counter electrode, $\mathrm{P}_{\mathrm{t}}$, and reference electrode, $\mathrm{SCE}$, used for our test.

3.2.1 Effect of layers coating on open circuit potential, Eoc of carbon steel:

Eoc measured for the substrate, $\mathrm{Cu}-\mathrm{Ni}$ coated, and $\mathrm{Cu}-\mathrm{Cu}-\mathrm{Ni}$ coated in fig.5.(a), The three layers located in region between No corrosion to corrosion and substrate located in corrosion.

3.2.2 Effect of P320, P600and P1200 on open circuit potential, Eoc at $1 \mathrm{gr} / \mathrm{L}$ graphene:

In fig.5. (b) that with $1 \mathrm{~g} / \mathrm{l} \mathrm{Gr}$ at $20 \mathrm{~min}$ on P600 surface finishing at $20 \mathrm{~min}$. rising from uncertainty regarding corrosion activity $\mathrm{V} \leq-0.20$ towards no corrosion occurred $\mathrm{V}>-0.20$ and, with $\mathrm{P} 320$ still in uncertainty regarding corrosion activity region $-0.35 \leq \mathrm{V} \leq-0.20$ within 300 (S).

(a)

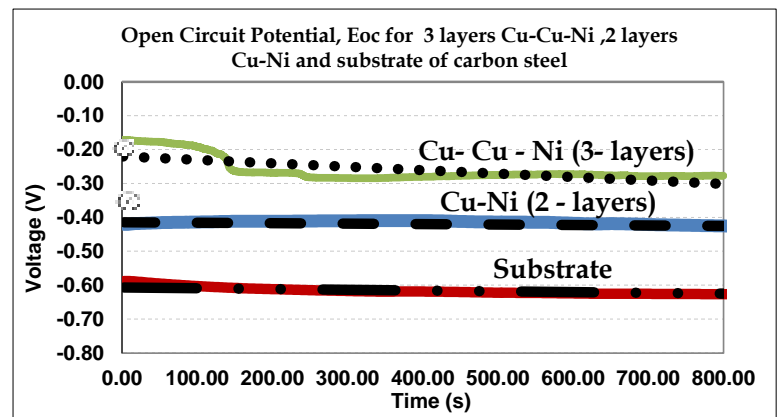

(b)

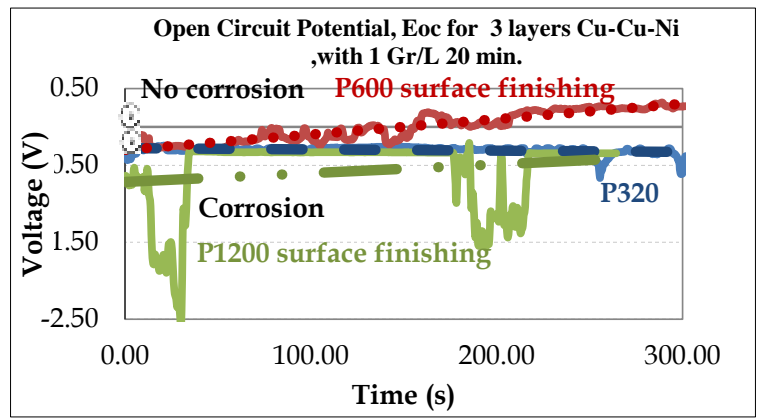

Figure 5. The Relation between Voltage (V) and Time(S) for Saline water (a) Multilayer of CuNi \& Carbon Steel, (b) Effect of the P320, P600and P1200 at $1 \mathrm{gr} / \mathrm{L}$ Gr

\subsection{The Tafel polarization test:}

3.3.1 The effect of layers coating on tafel polarization test of carbon steel:

Tafel polarization test measured for the substrate, $\mathrm{Cu}-\mathrm{Ni}$ coat, and $\mathrm{Cu}-\mathrm{Cu}-\mathrm{Ni}$ coat. The voltage of corrosion goes from -884 to -404 volt by coating as shown in Figure 6 (a).

\subsubsection{Effect of P320, P600and P1200 on tafel polarization at $1 \mathrm{~g} / \mathrm{l}$ graphene $20 \mathrm{~min}$ :}

Tafel polarization test measured for $\mathrm{Cu}-\mathrm{Cu}-\mathrm{Ni}$ coated by $1 \mathrm{~g} / \mathrm{l} \mathrm{Gr} 20 \mathrm{~min}$. P600 and P320 achieved for less corrosion than P 1200 where, shown in Figure 6.(d) and table 2.

Table 2. Tafel Polarization Resistance Results for $1 \mathrm{~g} / \mathrm{l}$ of Graphene $20 \mathrm{~min}$. between 3 Layers $\mathrm{Cu}-\mathrm{Cu}$-Ni Coating in Saline Water.

\begin{tabular}{|c|c|c|c|}
\hline Tafel polarization Resistance & $\mathbf{1 ~ g / l ~ 3 2 0}$ & $\mathbf{1} \mathbf{g} / \mathbf{l ~ 6 0 0}$ & $\mathbf{1} \mathbf{~ g / l ~ 1 2 0 0}$ \\
\hline Lower Fit Limit ( mV vs. Ref. (Pt) ) & -1139 & -924.7 & -1268 \\
\hline Upper Fit Limit ( mV vs. Ref. (Pt) ) & 1179 & 1473 & 1115 \\
\hline Beta A ( V/decade ) & 1.33 & 1.24 & 0.56 \\
\hline Beta C ( V/decade ) & 0.98 & 0.76 & 0.28 \\
\hline Icorr ( uA ) & 0.1408 & 0.001546 & 956 \\
\hline Ecorr ( mV ) & -374 & -271 & -751 \\
\hline Rp ( ohms ) & 1738000 & 132400000 & 84.84 \\
\hline Corrosion Rate ( mpy ) & 0.1072 & 0.001178 & 728.1 \\
\hline Protection efficiencies (PE \%) & 100 & 100 & 98.5 \\
\hline The porosity percentage (PP \%) & 0.0001 & 0.000001 & 1.82 \\
\hline
\end{tabular}


3.3.3 Effect of P320, P600, and P1200 on corrosion rate (mpy) and protection efficiencies PE (\%) with 1 and $2 \mathrm{~g} / \mathrm{l}$ graphene

The corrosion rate and protection efficiencies for a specific time of Gr's coating calculated as an explanation to the equation (2.8), where the results shown increase in protection efficiencies laded to decreasing in the corrosion rate, at $1 \mathrm{~g} / \mathrm{l} \mathrm{Gr}$ at $20 \mathrm{~min}$, Corrosion rate for P600 was the least $0.001 \mathrm{mpy}$ with the biggest protection efficiencies $100 \%$, where The obtained experimental results are compared with results of $\mathrm{K}$. Ollik and M. Lieder [10] with a good agreement ,at2 $\mathrm{g} / \mathrm{l} \mathrm{Gr}$ at $10 \mathrm{~min}$. corrosion rate for P600 was the least 48.95 mpy with protection efficiencies $67.42 \%$.

(a)



(c)

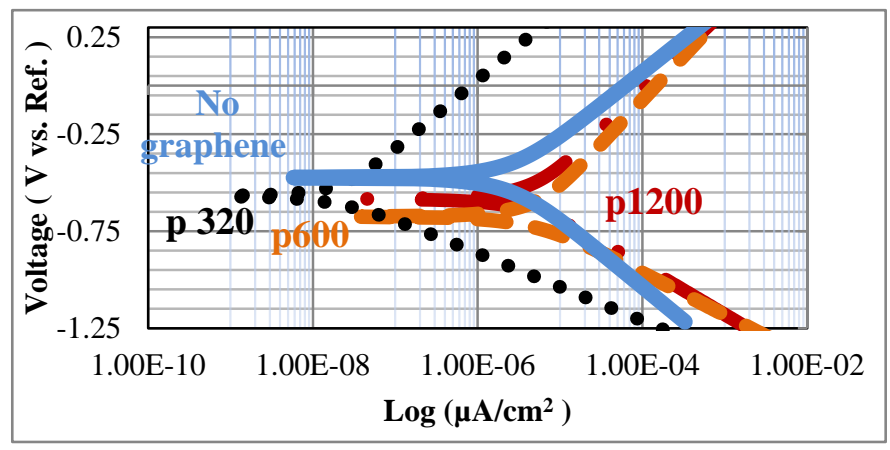

(b)



(d)

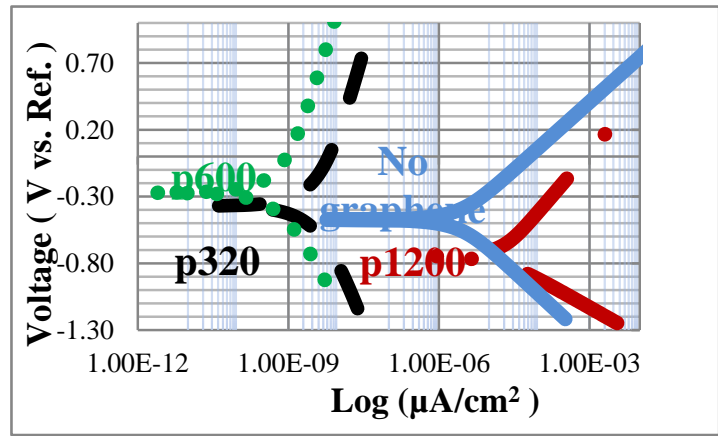

(e)

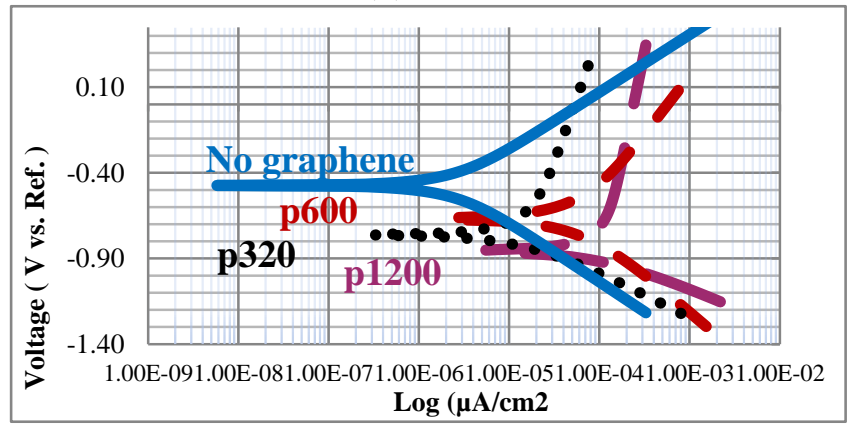

Figure 6. The Tafel Plot Relation Between Voltage (V) and $\log \left(\mu \mathrm{A} / \mathrm{cm}^{2}\right)$ for Saline Water of Measured for (a) Multi-Layers Coating on Carbon Steel,(b) Concentration 0.25 Gr /L,(c) Concentration $0.5 \mathrm{Gr} / \mathrm{L}$,(d) Concentration $1 \mathrm{Gr} / \mathrm{L}$, and (e) Concentration $2 \mathrm{Gr} / \mathrm{L}$ Electroplating on $\mathrm{Cu}-\mathrm{Cu}-\mathrm{Ni}$ Coated Carbon Steel with \& without Graphene. 


\subsection{The electrochemical impedance spectroscopy (EIS):}

3.4.1 Effect of coating $\mathrm{Cu}-\mathrm{Cu}-\mathrm{Ni}$ on carbon steel on electrochemical impedance spectroscopy (EIS):

EIS measured in Figure 7. (a) The values of ECE's for Nyquist plot with no Gr, Where, total R 1.73E+04 ohm. And also, Ccoat was 4.98E-06 (F) and CdL was 4.38E-05 (F).

3.4.2 Effect of P320, P600, and P1200 in Cu-Cu-Ni at 0.25, 0.5, and $1 \mathrm{~g} / \mathrm{l} \mathrm{Gr}$ on steel by EIS:

EIS for P320, P600, and P1200 with $0.25,0.5$ and $1 \mathrm{~g} / \mathrm{l} \mathrm{Gr}$ on steel in saline water shown in Figure 7.(b)-(d) , where the values of ECE's were respectively at $\mathbf{0 . 2 5} \mathbf{~ g / l ~ G r}$, at P320the highest total R $2.20 \mathrm{E}+04 \mathrm{ohm}, \mathrm{C} 1.60 \mathrm{E}-5 \mathrm{~F}$. At $\mathbf{0 . 5} \mathbf{~ g / l ~ G r}$, the highest total R $2.20 \mathrm{E}+04 \mathrm{ohm}$ at P320 the lowest total $R$ 5.94E+03 ohm at P600, the highest total R 1.07E+12 ohm , C 7.30E+2 F at P600 the lowest total R $1.00 \mathrm{E}+02 \mathrm{ohm}$ at P320, C 5.17E-08 F at P1200.At 1 g/l Gr, at P600, the highest total $\mathrm{R} 2.19 \mathrm{E}+04$ ohm at P600, C 1.29E-5 F at P1200and the lowest total R 1.28E+04 ohm at P1200, C 6.03E-6 F at 320 .

(a)



(c)

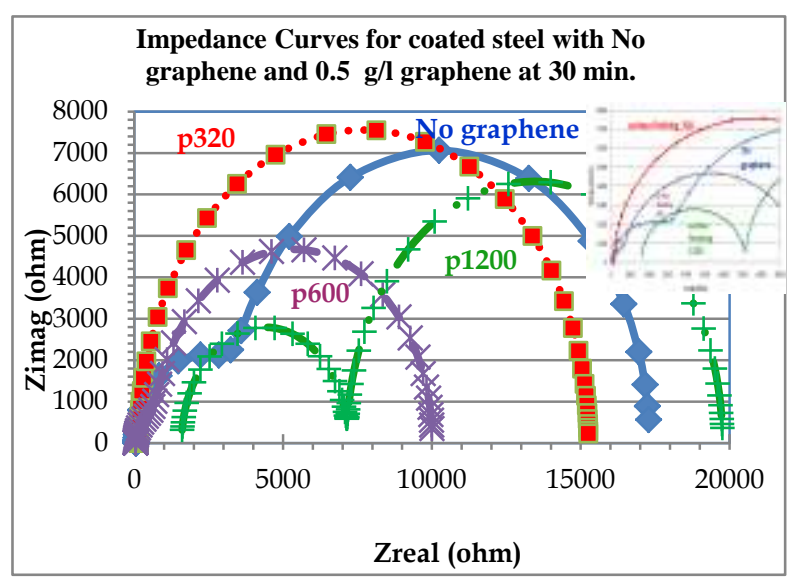

(b)



(d)

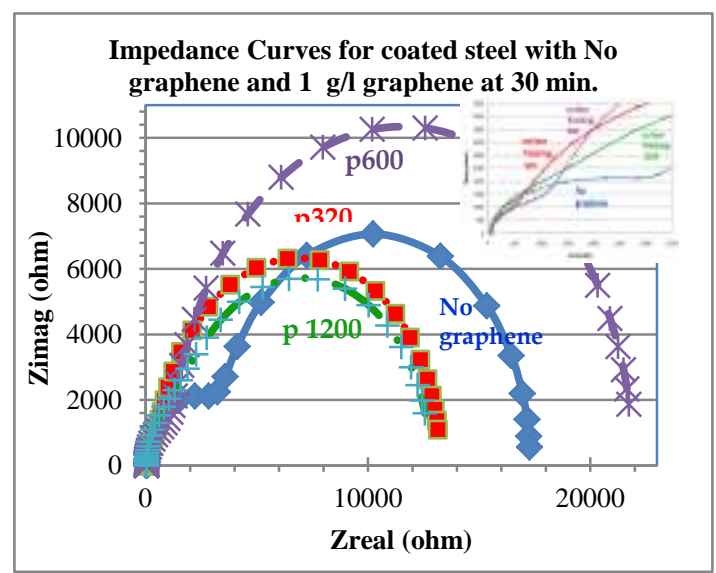

Figure 7. EIS Nyquist Plot Between -Zimag ( ohm )and Zreal (ohm) (a) Coating Cu-Cu-Ni on Carbon Steel,(b)-(d) P320, P600, and P1200 in Saline Water, (b)with 0.25 g/l Gr,(c) with 0.5 g/l Gr ,and (d) with 1 g/l Gr. 


\section{Conclusions:}

The effect of studying different concentrations of graphene with different times and different surface on coated steel leads to the following conclusions:

1. The morphology of coating was spongier as shown in microscope in the inner faces than the outer faces of electrodes of the cells coating.

2.The protection efficiencies were decreasing by 99.6, 99.2, 95.1and55.4\% with increasing concentration of graphene coating $0.25,0.5,1$ and $2 \mathrm{~g} / \mathrm{l}$ respectively between layers. The corrosion rates were increasing by $0.6,1.1,6.9$ and $67 \mathrm{mpy}$ with increasing concentration of graphene coating $0.25,0.5,1$ and $2 \mathrm{~g} / \mathrm{l}$ respectively between layers.

3. The types of corrosion were pitting corrosion, where the highest protection against corrosion were at concentration $1 \mathrm{~g} / \mathrm{l}$ at $20 \mathrm{~min}$ Gr coating with P600 and P320 mesh surfaces finishing were corrosion rate 0.001178 and $0.1072 \mathrm{mpy}$, PE \% 100,100,PP \% 0.000001, 0.0001,Rp 132400000, $1738000 \mathrm{ohm}$ respectively in saline water. where The obtained experimental results are compared with results of $\mathrm{K}$. Ollik and M. Lieder [10] with a good agreement . The next protection against corrosion were at concentration $0.5 \mathrm{~g} / \mathrm{l}$ at $30 \mathrm{~min}$ Gr coating with P320 mesh surfaces finishing were corrosion rate 0.1615 mpy,protection efficiencies $99.7 \%$,porosity percentages $0.4 \%$,polarization resistances 444.5 ohm .

4. The protection achieved by increasing the pore resistance $R_{\text {pore }}$ ohms of coating accompanied with decreasing of $\mathrm{C}_{\text {coat }} \mathrm{F}, \mathrm{R}_{\mathrm{p}}$ ohms and $\mathrm{C}_{\mathrm{dl}} \mathrm{F}$, with increasing of $\mathrm{R}_{\mathrm{u}}$. For ECE's were At P320: All elements decreasing but, Rp increasing at $5 \mathrm{~min}$ and $30 \mathrm{~min}$, and Rpore increasing at $0.5,1 \mathrm{~g} / \mathrm{l}, 20 \mathrm{~min}$ and 30 min, At P600:All elements decreasing but, Rp increasing at $5 \mathrm{~min}$ and $30 \mathrm{~min}$ by increasing concentration, and Rpore increasing at 0.5,1g/1, $20 \mathrm{~min}$ and $30 \mathrm{~min}$. and At P1200:All elements decreasing but, $\mathrm{Rp}$ increasing at $5 \mathrm{~min}$ and $30 \mathrm{~min} 0.5 \mathrm{~g} / \mathrm{l}$ by increasing concentration, and Rpore increasing at $0.5,1 \mathrm{~g} / \mathrm{l}, 20 \mathrm{~min}$ and $30 \mathrm{~min}$.

\section{Acknowledgements:}

I would like to express all my sincere thanks to my great supervisors who share with me their knowledge, efforts and time. I am indeed grateful for such chance that allowed me to benefit from their knowledge thank you for your advice that has a great impact on completion of our research. Finally yet importantly, I would like to thank my parents and my wife for their constant help, moral support and encouragement. Without their help, this work would have never seen the light day.

\section{REFERENCES}

[1] S. R. Cross, "Computational Modeling and Design of Multilayer Corrosion Coatings for Galvanic Protection of Steel," Massachusetts Institute of Technology, 2015.

[2] K. K. Kar, J. K. Pandey, and S. Rana, "Advances in Carbon Nanotube Technology for Corrosion Applications," in Handb. Polym. Nanocomposites. Process. Perform. Appl. Vol. B Carbon Nanotub. Based Polym. Compos., Springer-Verlag Berlin Heidelberg, 2015, pp. 335356.

[3] R. Afif Anaee, A. M. Al-Ghaban, and D. A. Abdullah, "Binary and Ternary Nanoceramic Coatings to Protect Carbon Steel in Artificial Seawater," Eng. \&Tech.Journal, vol. 34, no. 15, pp. 2854-2863.

[4] K. B. D. Prasai, J. Tuberquia, R. Harl, G. K. Jennings, B. Rogers, "Graphene : CorrosionInhibiting Coating," Am. Chem. Soc., vol. 6, no. 2, pp. 1102-1108, 2012.

[5] N. T. Kirkland, T. Schiller, N. Medhekar, and N. Birbilis, "Exploring graphene as a corrosion protection barrier," Corrosion Science, vol. 56. Pergamon, pp. 1-4, 01-Mar-2012. 
[6] E. Sutter, P. Albrecht, F. E. Camino, and P. Sutter, "Monolayer graphene as ultimate chemical passivation layer for arbitrarily shaped metal surfaces," Carbon N. Y., vol. 48, no. 15, pp. 4414-4420, Nov. 2010.

[7] N. W. Pu, C. A. Wang, Y. M. Liu, Y. Sung, D. S. Wang, and M. Der Ger, "Dispersion of graphene in aqueous solutions with different types of surfactants and the production of graphene films by spray or drop coating," J. Taiwan Inst. Chem. Eng., vol. 43, no. 1, pp. 140146, 2012.

[8] E. U. Pulido-Barragán, A. B. Morales-Cepeda, C. F. Castro-Guerrero, A. Koschella, and T. Heinze, "Upgrading Euphorbia Antisyphilitica fiber compost: A waste material turned into nanocrystalline cellulose," Ind. Crops Prod., vol. 160, Feb. 2021.

[9] D. S. Chauhan, M. A. Quraishi, K. R. Ansari, and T. A. Saleh, "Graphene and graphene oxide as new class of materials for corrosion control and protection: Present status and future scenario," Prog. Org. Coatings, vol. 147, no. January, 2020.

[10] I. V. G. and A. A. F. K. S. Novoselov, A. K. Geim, S. V. Morozov, D. Jiang, Y. Zhang, S. V. Dubonos, "Electric Field Effect in Atomically Thin Carbon Films," in science, vol. VOL 306, no. Science 306 (5696), 666-669, 2004, pp. 666-669.

[11] and P. A. Yu-Ming Lin, Keith A. Jenkins, Alberto Valdes-Garcia, Joshua P. Small, Damon B. Farmer, "Operation of Graphene Transistors at Gigahertz Frequencies," Nano Lett., vol. 9, no. 1, pp. 422-426, 2009.

[12] H.Strow,O.Products, "Copper alloy plating," in Surface Engineering, vol. 5, no. 1, the ASM International Handbook Committee, 2002, pp. 573-579.

[13] S. Singh, S. Samanta, A. K. Das, and R. R. Sahoo, "Tribological investigation of Ni-graphene oxide composite coating produced by pulsed electrodeposition," Surfaces and Interfaces, vol. 12, pp. 61-70, 2018.

[14] N. H. Pliny, "Corrosion Prevention by Coatings," in Corrosion Science and Engineering, Engineering Materials, Springer Nature Switzerland AG, 2018, pp. 327-361.

[15] R. K. Singh Raman et al., "Protecting copper from electrochemical degradation by graphene coating," Carbon N. Y., vol. 50, no. 11, pp. 4040-4045, 2012.

[16] Y. Raghupathy, A. Kamboj, M. Y. Rekha, N. P. Narasimha Rao, and C. Srivastava, "Coppergraphene oxide composite coatings for corrosion protection of mild steel in $3.5 \% \mathrm{NaCl}$," Thin Solid Films, vol. 636, pp. 107-115, 2017.

[17] H. S. Maharana, P. K. Rai, and A. Basu, "Surface-mechanical and electrical properties of pulse electrodeposited $\mathrm{Cu}$-graphene oxide composite coating for electrical contacts," $J$. Mater. Sci., vol. 52, no. 2, pp. 1089-1105, 2017.

[18] R. Zhang, G. Cui, X. Su, X. Yu, and Z. Li, "A novel functionally graded Ni-graphene coating and its corrosion resistance," J. Alloys Compd., vol. 829, p. 154495, Jul. 2020.

[19] C. M. P. Kumar, T. V. Venkatesha, and R. Shabadi, "Preparation and corrosion behavior of $\mathrm{Ni}$ and Ni-graphene composite coatings," Mater. Res. Bull., vol. 48, no. 4, pp. 1477-1483, 2013.

[20] G. Yasin et al., "Exploring the Nickel-Graphene Nanocomposite Coatings for Superior Corrosion Resistance: Manipulating the Effect of Deposition Current Density on its Morphology, Mechanical Properties, and Erosion-Corrosion Performance," Adv. Eng. Mater., vol. 20, no. 7, pp. 1-12, 2018.

[21] A. Tiwari and R. K. S. Raman, "Long-term corrosion protection of a Cupro-Nickel alloy due to graphene coating," Coatings, vol. 7, no. 12, pp. 1-15, 2017.

[22] Q. Zhou, J. Jiang, Q. Zhong, Y. Wang, K. Li, and H. Liu, "Preparation of Cu-Ni-Fe alloy 
coating and its evaluation on corrosion behavior in $3.5 \% \mathrm{NaCl}$ solution," J. Alloys Compd., vol. 563, pp. 171-175, 2013.

[23] Q. Do et al., "Effect of cupric sulfate on the microstructure and corrosion behavior of nickelcopper nanostructure coatings synthesized by pulsed electrodeposition technique," Corros. Sci., vol. 147, pp. 246-259, 2019.

[24] A. Groysman, "Corrosion for everybody," in Corrosion for Everybody, 2010, pp. 1-368.

[25] G. Instruments, "Potentiodynamic and Cyclic Polarization Scans," 2019. [Online]. Available: www.gamry.com.

[26] G. Instruments, "Getting Started with Electrochemical Corrosion Measurement," Gamry Instruments Inc, 2017. [Online]. Available: https://www.gamry.com/applicationnotes/corrosion-coatings/basics-of-electrochemical-corrosion-measurements/. [Accessed: 21Dec-2019].

[27] G. Instruments, "Gamry EIS part 1 - The Basics of Electrochemical Impedance Spectroscopy," 2017. [Online]. Available: https://www.gamry.com/resources/white-papers/. [Accessed: 21-Dec-2019].

[28] N. Wagner, "Electrochemical impedance spectroscopy," PEM Fuel Cell Diagnostic Tools, no. 1, pp. 37-70, 2011.

[29] F. González, D. Greiner, V. Mena, R. M. Souto, J. J. Santana, and J. J. Aznárez, "Fitting procedure based on Differential Evolution to evaluate impedance parameters of metal-coating systems," Eng. Comput. (Swansea, Wales), vol. 36, no. 9, pp. 2960-2982, 2019.

[30] S. Harb, F. dos Santos, S. Pulcinelli, C. Santilli, K. Knowles, and P. Hammer, "Protective Coatings Based on PMMA-Silica Nanocomposites Reinforced with Carbon Nanotubes," in Carbon Nanotubes - Current Progress of their Polymer Composites, no. july, INTECH, 2016, pp. 195-225.

[31] R. Anaee, A. Al-Ghaban, and D. Abdullah, "Estimation the Efficiency of Nano Particles Coating on Carbon Steel by Atomization," Eng\&Tech.Journal, vol. 34, no. 5, pp. 876-886, 2016.

[32] R. A. Majed, "Effect of Molybdate Anions On Corrosion Behavior of Stainless Steel 304 In 0.1M Nacl Solution," Eng. Tech. J., vol. 27, p. 16, 2009. 